\title{
CORRESPONDENCE
}

\section{Abnormal hand position leading to possible brachial plexus injury during spinal interventional neuroradiology: Are we aware of it?}

\author{
Amarjyoti Hazarika, Shailendra Kumar, \\ Meena Singh ${ }^{1}$
}

Interventional neuroradiology (IN) executes a diverse intervention from coiling of intracranial aneurysm to extracranial embolisation of spinal cord arterial venous malformations. In all these procedures, patients are required to be anaesthetised for zero motion during the "road mapping" ${ }^{[1]}$ of the vascular structure. This is more so important when spinal vascular structure is involved. Any wrong embolisation of this vasculature may lead to the spinal cord ischaemia and render the person paralytic.

Spinal cord vascular interventions especially of the thoracic and upper lumbar region have an inherent problem of artifacts due to upper limbs during imaging. For precise location of feeders and draining vessels of the vascular abnormalities, digital subtraction angiography (DSA) has to cover a large area in the vicinity of the abnormality and the upper limb by the patient's side or over the chest invariably interferes with the imaging. So to overcome, the hands are usually abducted to $120^{\circ}$ and beyond with elbows flexed about $90^{\circ}$ [Figure 1]. This may lead to brachial plexus injury. But equipment for DSA does not permit to keep the hand in the position prescribed because this reduces their maneuverability. Moreover, intervention of spinal vessel is a prolonged procedure and positioning the upper limb inappropriately under muscle relaxant for such a long time may lead to permanent disability.

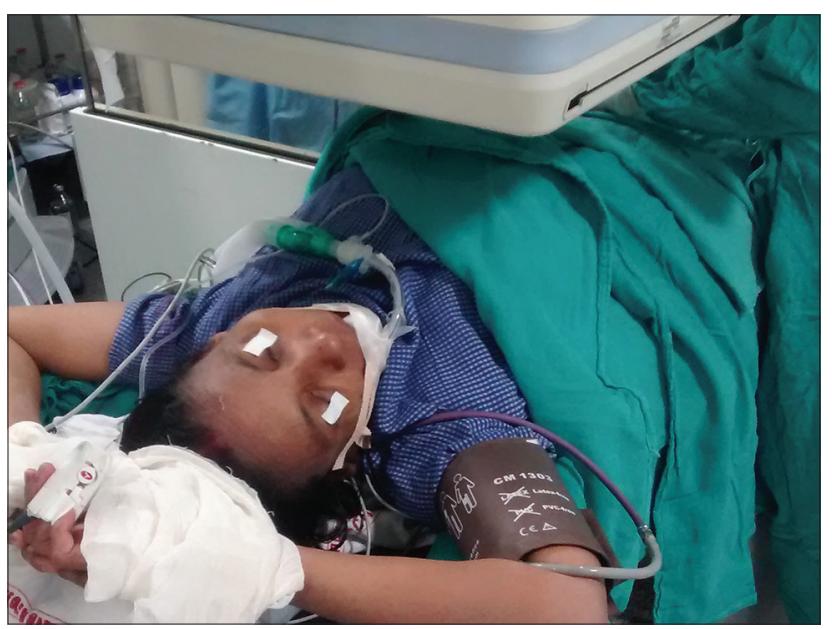

Figure 1: Shows arms are abducted more than 90 degree at shoulder joints

Proximally, the brachial plexus is anchored to vertebrae and prevertebral fascia, while distally it is anchored to the axillary sheath, stretching brachial plexus causing injury to the nerve. ${ }^{[2]}$ Several factors predispose to plexus injuries, including $90^{\circ}$ or greater arm abduction, extension of the upper extremity, external rotation of the upper extremity. ${ }^{[3]}$ Pillai et al. have mentioned the grave risk of plexus injury during IN if the arms are abducted beyond $90^{\circ} .^{[4]}$ Preventive measures are to maintain flexion of all joints of the upper limbs below $90^{\circ} .{ }^{[5]}$ There are no specific guidelines in the literature to prevent plexus injury during spinal IN nor any modification have been made in the design and function of the imaging equipment to overcome interference from normally placed hands. It is imperative for everyone to have knowledge about this danger while performing spinal IN procedure and appropriate measures should be taken for carrying out intervention without injuring the neural structures.

\section{REFERENCES}

1. Dodson BA. Interventional neuroradiology and management of patients with arteriovenous malformation. In: Cottrell JE, Smith DS, editors. Anaesthesia and Neurosurgery. $4^{\text {th }}$ ed. St. Louis: Mosby; 2001. p. 409-11.

2. Bhardwaj D, Peng P. An uncommon mechanism of brachial plexus injury. A case report. Can J Anaesth 1999;46:173-5.

Department of Neuroanaesthesiology, Neuroscience Centre, AlIMS, 'Department of Anaesthesiology, J.P.N.A.T.C., AlIMS, New Delhi, India 
3. Winfree $\mathrm{CJ}$, Kline DG. Intraoperative positioning nerve injuries. Surg Neurol 2005;63:5-18.

4. Pillai AK, Ferral H, Desai S, Paruchuri S, Asselmeier S, Perez-Gautrin R. Brachial plexus injury related to patient positioning. J Vasc Interv Radiol 2007;18:833-4.

5. Cooper DE, Jenkins RS, Bready L, Rockwood CA Jr. The prevention of injuries of the brachial plexus secondary to malposition of the patient during surgery. Clin Orthop Relat Res 1988;33-41.

\begin{tabular}{|l|l|}
\hline \multicolumn{2}{|c|}{ Access this article online } \\
\hline Quick Response Code: & Website: \\
\hline & www.jnaccjournal.org \\
\cline { 2 - 2 } & \\
\hline
\end{tabular}

